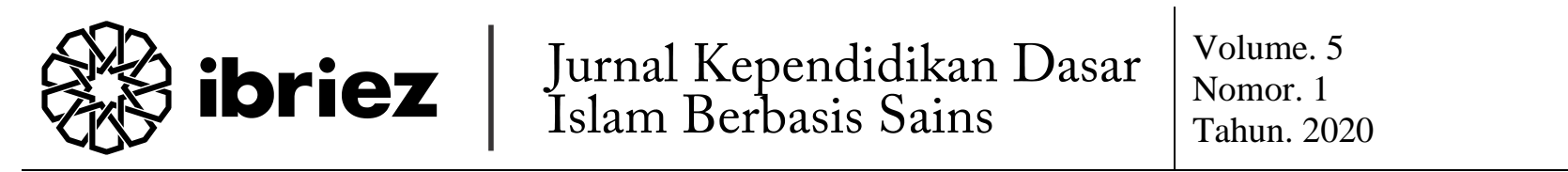

\section{Hubungan Pola Asuh Orang Tua dengan Perilaku Sopan Santun Siswa Kelas III MI Nurul Ulum Sidorejo Madiun}

\author{
Avita Febri Hidayana ${ }^{1}$ dan Siti Fatonah ${ }^{2}$ \\ Universitas Islam Negeri Sunan Kalijaga Yogyakarta \\ Surel: avitafebri@gmail.com¹ ${ }^{1}$ sitifat31@gmail.com²
}

\begin{abstract}
Abstrak
Penelitian ini mengenai hubungan antara pola asuh orang dan perilaku sopan santun siswa kelas III MI Nurul Ulum Sidorejo, yang memiliki tujuan yaitu (1) mengetahui pola asuh orang tua siswa kelas III MI Nurul Ulum Sidorejo, (2) mengetahui perilaku sopan santun siswa kelas III MI Nurul Ulum Sidorejo, dan (3) mengetahui hubungan antara pola asuh orang dengan perilaku sopan santun siswa kelas III MI Nurul Ulum Sidorejo. Penelitian ini dilakukan dengan menggunakan rancangan penelitian kuantitatif yang terdiri dari dua variabel, yaitu pola asuh orang tua sebagai variabel bebas dan perilaku sopan santun sebagai variabel terikat. kesimpulan dalam penelitian ini yaitu (1) sebanyak 15 anak (39,47\%) memiliki pola asuh demokratis, sebanyak 10 anak (26,31\%) memiliki pola asuh situasional, sebanyak 8 anak (21,05\%) memiliki pola asuh permitif, sebanyak 3 anak $(7,89 \%)$ memiliki pola asuh laisses fire, dan sebanyak 2 anak (5,26\%) memiliki pola asuh otoriter, (2) sebanyak 21 anak memiliki kategori perilaku sopan santun yang baik, 10 anak memiliki perilaku sopan santun sedang, dan 7 anak memiliki perilaku sopan santun buruk, (3) terdapat korelasi yang positif antara antara pola asuh orang dengan perilaku sopan santun siswa kelas III MI Nurul Ulum Sidorejo. Selain itu, untuk tingkat hubungannya 0,639 memiliki tingkat hubungan yang kuat. Hal tersebut sesuai dengan kriteria dari tabel interpretasi korelasi nilai $r$.
\end{abstract}

Kata Kunci: Pola Asuh, Orang Tua, Perika Sopan Santun

\section{Abstract}

This research is about the relationship between parenting style and manners behavior of third grade MI Nurul Ulum Sidorejo students. Whose aim is : (1) to know the parenting style of third grade MI MI Nurul Ulum Sidorejo students, (2) understanding the behavior of class III MI students. MI Nurul Ulum Sidorejo, and (3) discover the relationship between parenting practices and the expression of class III students' manners MI Nurul Ulum Sidorejo. This research was conducted using a quantitative research design consisting of two variables: parenting as an independent variable and courtesy behavior as a dependent variable. The conclusions in this study: First, 15 children (39.47\%) have democratic parenting, 10 children 
(26.31\%) have situational parenting, 8 children (21.05\%) have permissive parenting, 3 children (7.89\%) had laisses fire parenting, and 2 children (5.26\%) had authoritarian parenting. Second, children had good manners, 10 children had good manners moderate, and 7 children have bad manners. Third, there is a positive correlation between people's parenting patterns and class III MI Nurul Ulum Sidorejo students' behavior. Besides, for the relationship level, 0.639 has a healthy relationship level. It is following the criteria of the correlation table interpretation of the value of $r$.

Keywords: Parenting, Parents, Polite Manners

\section{Pendahuluan}

Keluarga merupakan lingkungan sosial yang pertama diperkenalkan kepada anak. Keluarga merupakan kelompok sosial terkecil yang umumnya terdiri atas ayah, ibu, dan anak. Hubungan sosial di antara anggota keluarga relatif tetap dan didasarkan atas ikatan darah, perkawinan dan/atau adopsi, yang dijiwai oleh suasana afeksi dan rasa tanggung jawab dalam memelihara, merawat, dan melindungi anak. ${ }^{1}$ Sehingga ayah dan ibu dalam suatu keluarga dapat dikatakan sebagai orang tua.

Peran orang tua bagi pendidikan anak adalah memberi dasar pendidikan, sikap, dan ketrampilan dasar, seperti pendidikan agama, budi pekerti, sopan santun estetika, kasih sayang, dan rasa aman, dasar-dasar untuk memenuhi peraturan-peraturan, dan menanamkan kebiasaan-kebiasaan. Selain itu orang tua juga mengajarkan nilai-nilai dan tingkah laku yang diajarkan di sekolah. $^{2}$ Hal tersebut dapat diajarkan dengan pola asuh masing-masing dari orang tua anak.

Pola asuh merupakan suatu cara yang dapat ditempuh orang tua dalam mendidik anak sebagai perwujudan dari

\footnotetext{
${ }^{1}$ Purwanto, Pengantar Pendidikan, 97.

${ }^{2}$ Noor, Orang Tua Bijaksana Anak Bahagia, 20.
}

rasa tanggung jawab kepada anakanaknya. ${ }^{3}$ Pola asuh orang tua juga membantu anak untuk mengembangkan disiplin diri, sehingga dapat diaktualisasikan terhadap penataan: lingkungan fisik, lingkungan sosial internal dan eksternal, pendidikan internal dan eksternal, dialong dengan anak, suasana psikologis, sosial budaya, kontrol terhadap perilaku anak-anak, menentukan nilai-nilai moral sebagai dasar berperilaku dan yang diupayakan kepada anak-anak. ${ }^{4}$ Salah satunyanya adalah sopan santun.

Sopan santun merupakan perwujudan budi pekerti luhur yang diperoleh melalui pengalaman, pendidikan, dan teladan dari orang tua, guru, para pemuka agama, serta tokohtokoh masyarakat. Sopan santun merupakan tata karma dalam kehidupan sehari-hari sebagai cerminan kepribadian dan budi pekerti luhur yang di dalam Islam lebih dikenal dengan konsep akhlak. ${ }^{5}$ Di mana keluarga atau orang tua memiliki peran penting dalam perilaku

\footnotetext{
${ }^{3}$ Mansur, Pendidikan Anak Usia Dini Dalam Islam, 305.

${ }^{4}$ Shochib, Pola Asuh Orang Tua, 15.

${ }^{5}$ Risthantri and Sudrajat, "HUBUNGAN ANTARA POLA ASUH ORANG TUA DAN KETAATAN BERIBADAH DENGAN PERILAKU SOPAN SANTUN PESERTA DIDIK."
} 
sopan santun anak, karena keluarga merupakan pendidikan pertama yang diperoleh anak.

Pembentukan sopan santun dimulai dari keluarga. Anak akan meniru perilaku orang tua dalam kehidupan sehar-hari. Anak yang mempunyai perilaku sopan pada umumnya berasal dari keluarga yang juga sopan, demikian pula sebaliknya anak yang mempunyai perilaku kasar tentunya perilaku keluarga juga kasar. Upaya menanamkan sopan santun di dalam keluarga yaitu dengan cara orang tua memberikan contohcontoh penerapan perilaku sopan santun di depan anak. ${ }^{6}$

Seiring perkembangan zaman dan canggihnya teknologi, banyak orang tua yang kurang peduli mengenai akhlak atau perilaku anak. Orang tua hanya melihat berhasil tidaknya anak secara akademik tanpa melihat dari sisi perilaku anak. Banyak anak secara akademik memiliki nilai yang baik namun perilaku sopan santun mereka kurang.

\section{Pola Asuh Orang Tua}

Pola asuh merupakan cara, metode atau strategi orang tua dalam mendidik anak-anaknya. Dalam kaitanya dengan pendidikan berarti orang tua memiliki tanggung jawab yang disebut tanggung jawab primer, yaitu tanggung jawab yang harus dikerjakan, apabila tidak dkerjakan maka anak-anaknya akan mengalami kebodohan dan lemah dalam menghadapi kehidupan. $^{7}$ Selain itu, pola asuh

\footnotetext{
${ }^{6}$ Mansur, Pendidikan Anak Usia Dini Dalam Islam, 192.

${ }^{7}$ Mansur, 350.
}

merupakan sejumlah model atau bentuk perubahan ekspresi dari orang tua yang dapat mempengaruhi potensi genetic yang melekat pada diri individu dalam upaya memelihara, merawat, membimbing, membina dan mendidik ana-anaknya baik yang masih kecil ataupun yang belum dewasa agar menjadi manusia dewasa yang mandiri dikemudian hari. ${ }^{8}$

Menurut Hurlack terdapat lima pola asuh orang tua yaitu (1) pola asuh otoriter yaitu pola asuh yang ditandai dengan cara mengasuh anak-anaknya dengan aturan-aturan ketat, seringkali memaksa anak untuk berperilaku seperti dirinya (orang tua), kebebasan untuk bertindak atas nama diri sendiri dibatasi. Pola asuh yang bersifat otoriter ini juga ditandai dengan hukuman yang dilakukan dengan keras, mayoritas hukuman tersebut sifatnya fisik. Pola asuh ini anak diibaratkan sebagai robot; (2) pola asuh demokratis yaitu pola asuh yang ditandai dengan pengakuan orang tua terhadap kemampuan anak-anaknya, dan kemudian anak-anak diberi kesempatan untuk tidak selalu tergantung kepada orang tua. Pola asuh ini ibarat jika ada masalah orang tua dan anak saling memberikan masukan dalam mengambil keputusan; (3) pola asuh laisses fire yaitu pola asuh dengan cara orang tua mendidik anak secara bebas, anak diangga orang dewasa atau muda, ia diberi kelonggaran seluas-luasnya apa saja yang dikehendaki serta tanpa teguran, arahan, atau bimbingan; (4) pola

\footnotetext{
${ }^{8}$ Anisah, "POLA ASUH ORANG TUA DAN IMPLIKASINYA TERHADAP PEMBENTUKAN KARAKTER ANAK."
} 
asuh situasional yaitu gabungan dari satu atau dua pola asuh sesuai dengan situasi tertentu, sehingga pola asuh ini disesuaikan dengan sikap anak dalam menanggapi orang tua; (5) pola asuh permitif yaitu kebalikan dari pola asuh otoriter yang mana dalam pola asuh permisif orang tua harus mengikuti keinginan anak baik orang tua setuju maupun tidak sehingga anak cenderung menjadi bertindak semena-mena, ia bebas melakukan apa saja yang diinginkannya tanpa memandang bahwa itu sesuai dengan nilai-nilai atau norma yang berlaku atau tidak. ${ }^{9}$

Menurut Yusuf terdapat empat prinsip peranan orang tua, antaralain: (1) modeling yaitu orangtua adalah contoh atau model bagi anak, serta model yang pertama dan terdepan bagi anak (baik positif atau negatif) dan merupakan pola bagi "way of life" anak, (2) mentoring yaitu kemampuan untuk menjalin atau membangun hubungan, investasi emosional (kasih sayang kepada orang lain) atau pemberian perlindungan kepada orang lain secara mendalam, jujur, pribadi dan tidak bersyarat, (3) organizing yaitu keluarga seperti perusahaan yang memerlukan kerjasama antar anggota keluarga dalam menyelesaikan tugastugas atau memenuhi kebutuhan keluarga, dan (4) teaching yaitu orang tua berperan sebagai guru bagi anak-anaknya tentang dasardasar kehidupan. Orang tua berupaya memberdayakan prinsip-prinsip

\footnotetext{
${ }^{9}$ Mansur, Pendidikan Anak Usia Dini Dalam Islam, 353-57.
}

kehidupan, sehingga anak memahami dan melaksanakannya. ${ }^{10}$

\section{Perilaku Sopan Santun}

Sopan santun merupakan suatu tata cara atau aturan yang turun-temurun dan berkembang dalam suatu budaya masyarakat, yang bermanfaat dalam pergaulan dengan orang lain, agar terjalin hubungan yang akrab, saling pengertian, hormat-menghormati menurut adat yang telah ditentukan. ${ }^{11}$ Sopan santun juga merupakan cerminan akhlak yang dapat dicapai melalui proses pembelajaran anak di sekolah. Transfer pengetahuan yang diukur dengan nilai belum mampu membentuk pribadi yang berakhlak mulia. Sopan santun justru bergantung pada bagaimana proses pembinaan akhlak anak. Akhlak selalu melekat dan tampak dalam bentuk perbuatan. ${ }^{12}$ Sehingga perilaku sopan santun merupakan sikap mengenai suatu aturan atau tata cara dalam kehidupan.

Perilaku sopan santun manusia dibentuk dari perilaku yang dipelajari, melalui berbagai cara antara lain (1) kebiasan yaitu perilaku yang dibentuk oleh kebiasaan sehari-hari seperti mengucapkan terimakasih ketika diberi barang orang lain, berdoa sebelum makan dan lain sebagainya; (2) pengertian yaitu perilaku yang dibentuk dengan adanya belajar, seperti kita harus menggunakan helm ketika mengendarai motor untuk

\footnotetext{
${ }^{10}$ Risthantri and Sudrajat, "HUBUNGAN ANTARA POLA ASUH ORANG TUA DAN KETAATAN BERIBADAH DENGAN PERILAKU SOPAN SANTUN PESERTA DIDIK." ${ }^{11}$ Suharti, "Pendidikan Sopan Santun Dan Kaitannya Dengan Prilaku Berbahasa Jawa Mahasiswa," 61. ${ }^{12}$ Mu'niah, Materi Pendidikan Agama Islam Untuk Perguruan Tinggi, 104.
} 
keselamatan diri kita, kita harus makanmakanan yang bergizi agar sehat dan terhidar dari penyakit; (3) menggunakan model yaitu perilaku yang dibentuk dengan mencontoh seseorang sebagai modelnya. ${ }^{13}$ Selain itu, terdapat faktor yang mempengaruhi perilaku sopan santun anak diantaranya pengawasan dari orang-orang sekitar, sosok teladan atau panutan anak, serta penanaman dari anak sejak kecil. ${ }^{14}$

Deskripsi perilaku sopan santun menurut Fathurrohman yaitu berperilaku sopan santun terhadap orang tua, saudara, teman, dan guru, tertib menurut adat yang baik, selalu baik budi bahasanya, selalu bertingkah laku menurut adat yang baik, selalu berpakaian sesuai dengan adat yang berlaku, suka merasa belas kasihan dan suka menolong orang yang kesusahan, berperilaku sopan santun dalam mengemukakan pikiran secara lisan atau tulisan dalam pergaulan sehari-hari, dan menghindarkan diri dari perilaku yang tidak sopan. ${ }^{15}$

Perilaku sopan santun memiliki banyak manfaat baik diantaranya (1) Damai, jika hidup dama maka akan jauh dari permusuhan, dengan selalu bersikap sopan santun, selain tak menambah musuh baru, secara perlahan juga dapat mengubah musuh lama menjadi sahabat baru, (2) Bahagia, sopan santun akan memberikan kebagiaan bagi orang-orang di sekitarnya. jika kita selalu bersikap

\footnotetext{
${ }^{13}$ Maulida, “Hubungan Pengunaan Bahasa Jawa Krama Dengan Perilaku Siswa MIN Kecandran Salatiga Tahun 2012," 38-40.

${ }^{14}$ Maulida, 40.

${ }^{15}$ Fathurrohman, Pengembangan Pendidikan Karakter, 142.
}

sopan santun dalam tindakan maupun sedang bertutur kata, maka akan membuat suasana bahagia bagi orangorang ada disekitar kita, (3) Dihargai dan dihormati, sopan santun akan memperkuat rasa hormat terhadap orang lain, jika kita selalu bersikap sopan santun maka kita akan selalu dihargai dan dihormati oleh orang lain, (4) Suasana komunikasi yang baik, sopan santun dapat menciptakan suasana komunikasi yang baik, jika kita sedang berhadapan dengan suatu masalah yang membutuhkan cara penyelesaian, dengan selalu bersikap sopan santun dalam bertutur kata, maka tidak akan membuat lawan komunikasi merasa marah atau kesal, sebaliknya jika kita bertutur kata kurang sopan makan permasalahan tidak akan selesai dengan baik, (5) Meluluhkan kemarahan, sopan santun dapat meluluhkan kemarahan. jika kita melakukan kesalah kepada orang lain segera minta maaf dengan sikap sopan santun dan tulus maka kesalahan kita akan dimaafkan oleh orang tersebut. ${ }^{16}$

\section{Metode Penelitian}

Penelitian ini menggunakan penelitian kuantitatif yang bersifat hubungan atau korelasional. Tujuan dari penelitian ini untuk melihat hubungan diantara dua variabel atau lebih. ${ }^{17}$ Variabel dalam penelitian ini yaitu pola asuh orang tua sebagai variabel bebas dan perilaku sopan santun sebagai variabel terikat.

\footnotetext{
${ }^{16}$ Wahyudi and Arsana, "PERAN KELUARGA DALAM MEMBINA SOPAN SANTUN ANAK DI DESA GALIS KECAMATAN GALIS KABUPATEN PAMEKASAN." ${ }^{17}$ Sugiyono, Metode Penelitian Pendidikan (Pendekatan Kuantitatif, Kualitatif, Dan R\&D), 38.
} 
Penelitian ini dilakukan pada tanggal 6 Maret 2020, berlokasi di MI Nurul Ulum Sidorejo Madiun, dengan populasi siswa kelas III dan sampel berjumlah 38 siswa. Teknik pengumpulan data dalam penelitian ini yaitu kuesioner atau angket untuk memperoleh data mengenai pola asuh orang tua dan perilaku sopan santun.

Teknik analisis data dalam penelitian ini yaitu pra penelitian menggunakan uji validitas dan reliabilitas, di mana instrumen yang valid dapat digunakan untuk mengukur apa yang seharusnya diukur. Sedangkan instrumen yang reliabel adalah instrumen yang bila digunakan beberapa kali untuk mengukur objek yang sama akan menghasilkan data yang sama. ${ }^{18}$

Uji prasyarat menggunakan uji normalitas dan linieritas, di mana tujuan dilakukannya uji normalitas terhadap serangkaian data adalah untuk mengetahui apakah populasi data berdistribusi normal atau tidak. sedangkan tujuan dilakukan uji linieritas adalah untuk mengetahui apakah variabel bebas dan variabel terikat mempunyai hubungan linier. ${ }^{19}$

Analisis data dalam penelitian ini menggunakan korelasi sederhana yang mana untuk menguji apakah terdapat hubungan antara pola asuh orang dan perilaku sopan santun siswa serta seberapa erat hubungannya. Dalam penelitian ini peneliti berbantuan aplikasi SPSS 16.00.

\footnotetext{
18 Sugiyono, 173.

${ }^{19}$ Siregar, Statistik Parametrik Untuk Penelitian Kuantitatif.
}

\section{Analisis Data}

1. Data mengenai Pola Asuh Orang Tua Siswa Kelas III MI Nurul Ulum Sidorejo

Hasil dari distribusi frekuensi relatif pola asuh orang tua siswa yaitu sebagai berikut.

Tabel I Distribusi Frekuensi Relatif Pola Asuh Orang Tua Siswa

\begin{tabular}{|c|c|c|}
\hline $\begin{array}{l}\text { Pola Asuh } \\
\text { Orang Tua }\end{array}$ & Frekuensi & Presentasi \\
\hline $\begin{array}{l}\text { Pola asuh } \\
\text { demokratis }\end{array}$ & 15 & $39,47 \%$ \\
\hline $\begin{array}{l}\text { Pola asuh } \\
\text { situasional }\end{array}$ & 10 & $26,31 \%$ \\
\hline $\begin{array}{l}\text { Pola asuh } \\
\text { permitif }\end{array}$ & 8 & $21,05 \%$ \\
\hline $\begin{array}{l}\text { Pola asuh } \\
\text { laisses fire }\end{array}$ & 3 & $7,89 \%$ \\
\hline $\begin{array}{l}\text { Pola asuh } \\
\text { otoriter }\end{array}$ & 2 & $5,26 \%$ \\
\hline Jumlah & 38 & 100,00 \\
\hline
\end{tabular}

Berdasarkan tabel tersebut sebanyak 15 anak $(39,47 \%)$ memiliki pola asuh demokratis, sebanyak 10 anak $(26,31 \%)$ memiliki pola asuh situasional, sebanyak 8 anak $(21,05 \%)$ memiliki pola asuh permitif, sebanyak 3 anak $(7,89 \%)$ memiliki pola asuh laisses fire, dan sebanyak 2 anak (5,26\%) memiliki pola asuh otoriter

2. Data mengenai Perilaku Sopan Santun Siswa Kelas III MI Nurul Ulum Sidorejo

Kategori perilaku sopan santun siswa kelas III, yang termasuk dalam kategori baik, sedang dan buruk dapat dilihat sebagai barikut. 
Tabel II Pengkategorian Perilaku Sopan

Santun Siswa

\begin{tabular}{|c|c|c|}
\hline Skor & Kategori & Frekuensi \\
\hline$>64,098$ & Baik & 21 \\
\hline $\begin{array}{c}64,098- \\
50,682\end{array}$ & Sedang & 10 \\
\hline$<50,682$ & Buruk & 7 \\
\hline \multicolumn{2}{|r|}{ Jumlah } & 38 \\
\hline
\end{tabular}

Dari tabel tersebut menunjukkan bahwa sebanyak 21 anak memiliki kategori perilaku sopan santun yang baik, 10 anak memiliki perilaku sopan santun sedang, dan 7 anak memiliki perilai sopan santun buruk
Dari tabel di atas menunjukkan bahwa nilai signifikansi sebesar 0,000 $<$ 0,05 sehingga menunjukkan terdapat korelasi yang positif antara antara pola asuh orang dengan perilaku sopan santun siswa kelas III MI Nurul Ulum Sidorejo. Selain itu, untuk tingkat hubungannya 0,614 memiliki tingkat hubungan yang kuat. Hal tersebut sesuai dengan kriteria dari korelasi nilai r yaitu. ${ }^{20}$

Tabel III Korelasi Pola Asuh Orang dengan Perilaku Sopan Santun Siswa

Correlations

\begin{tabular}{|ll|r|r|}
\hline & & $\begin{array}{c}\text { Pola Asuh } \\
\text { Orang_Tua }\end{array}$ & $\begin{array}{c}\text { Perilaku } \\
\text { Sopan_Santun }\end{array}$ \\
\hline Pola Asuh Orang Tua & Pearson Correlation & 1 &. $\mathbf{6 3 9}^{* *}$ \\
& Sig. (2-tailed) & 38 & $\mathbf{. 0 0 0}$ \\
& $\mathrm{N}$ & $.639^{* *}$ & 38 \\
\hline Perilaku Sopan Santun & Pearson Correlation & .000 & 1 \\
& Sig. (2-tailed) & 38 & 38 \\
& $\mathrm{~N}$ & & \\
& & & 38 \\
\hline
\end{tabular}

**. Correlation is significant at the 0.01 level (2-tailed).

3. Data mengenai Pola Asuh Orang dengan Perilaku Sopan Santun Siswa Kelas III MI Nurul Ulum Sidorejo

Hasil penelitian menunjukkan bahwa hubungan antara pola asuh orang dengan perilaku sopan santun siswa memiliki korelasi sebesar 0,639 . Untuk mengetahui lebih lanjut berikut hasil perhitungannya.
Tabel IV Interpretasi Koefisien Korelasi Nilai r

\begin{tabular}{|c|c|}
\hline $\begin{array}{c}\text { Interval } \\
\text { Koefisien }\end{array}$ & $\begin{array}{c}\text { Tingkat } \\
\text { Hubungan }\end{array}$ \\
\hline $0,800-$ & Sangat Kuat \\
1,000 & \\
\hline $0,600-$ & Kuat \\
0,799 & \\
\hline $0,400-$ & Cukup Kuat \\
0,599 & \\
\hline
\end{tabular}

${ }^{20}$ Wulansari, Penelitian Pendidikan: Suatu Pendekatan Praktik Dengan Menggunakan SPSS, 97. 


\begin{tabular}{|c|c|}
\hline $0,200-$ & Rendah \\
0,399 & \\
\hline $0,000-$ & Sangat \\
1,999 & Rendah \\
\hline
\end{tabular}

Hal tersebut sesuai dengan penelitian yang dilakukan oleh Rohner dalam buku Masnur, hasil penelitian menunjukkan bahwa pola asuh orang tua, baik yang menerima atau yang menolak anaknya, akan mempengaruhi perkembangan emosi, perilaku, sosial-kognitif, dan kesehatan fungsi psikologisnya ketika dewasa kelak. $^{21}$ Hal tersebut menunjukkan bahwa terdapat hubungan antara pola asuh orang tua dengan perilaku sopan santun anak.

Selain itu, dalam jurnal Anisah menyebutkan bahwa perhatian, kendali dan tindakan orang tua merupakan salah satu bentuk pola asuh yang akan memberikan dampak panjang terhadap kelangsungan perkembangan fisik dan mental anak. $^{22}$ Penelitian lain juga menyebutkan bahwa pembentukan sopan santun dimulai dari keluarga yang memberikan contoh baik secara langsung maupun tidak langsung. Anak akan meniru perilaku orang tua dalam kehidupan sehar-hari. Anak yang mempunyai perilaku sopan dapat dipastikan keluarganya juga sopan, demikian pula sebaliknya anak yang mempunyai perilaku kasar

\footnotetext{
${ }^{21}$ Muslich, Pendidikan Karakter Menjawab Tantangan Krisis Multidimensional, 103.

${ }^{22}$ Anisah, "POLA ASUH ORANG TUA DAN IMPLIKASINYA TERHADAP PEMBENTUKAN KARAKTER ANAK," 71.
}

tentunya perilaku keluarga juga kasar. $^{23}$

\section{Simpulan}

Berdasarkan mengenai hubungan pola asuh orang dengan perilaku sopan santun siswa kelas III MI Nurul Ulum Sidorejo dapat disimpulkan bahwa:

1. Sebanyak 15 anak $(39,47 \%)$ memiliki pola asuh demokratis, sebanyak 10 anak $(26,31 \%)$ memiliki pola asuh situasional, sebanyak 8 anak (21,05\%) memiliki pola asuh permitif, sebanyak 3 anak $(7,89 \%)$ memiliki pola asuh laisses fire, dan sebanyak 2 anak (5,26\%) memiliki pola asuh otoriter.

2. Sebanyak 21 anak memiliki kategori perilaku sopan santun yang baik, 10 anak memiliki perilaku sopan santun sedang, dan 7 anak memiliki perilaku sopan santun buruk .

3. Terdapat hubungan yang positif antara antara pola asuh orang dengan perilaku sopan santun siswa kelas III MI Nurul Ulum Sidorejo. Selain itu, untuk tingkat hubungannya 0,639 memiliki tingkat hubungan yang kuat. Hal tersebut sesuai dengan kriteria dari korelasi nilai $r$.

Sehingga dapat disimpulkan bahwa pola asuh orang tua memiliki peran penting dalam perilaku sopan santun anak. Semakin baik pola asuh orang tua semakin baik pula perilaku sopan santun siswa, sebaliknya semakin kurang atau

\footnotetext{
${ }^{23}$ Risthantri and Sudrajat, "HUBUNGAN ANTARA POLA ASUH ORANG TUA DAN KETAATAN BERIBADAH DENGAN PERILAKU SOPAN SANTUN PESERTA DIDIK," 200.
} 
tidak tepat pola asuh orang tua semakin kurang juga perilaku sopan santun siswa.

Orang tua akan menerapkan dan memilih pola asuh tertentu sesuai dengan situasi dan kondisi masing-masing anak. Orang tua juga harus menanamkan kesopanan dengan menerapkan nilai-nilai norma ke dalam diri anak serta memberikan contoh dan keteladanan dengan berperilaku sesuai dengan nilainilai moral dan merealisasikan nilai-nilai moral dalam kehidupan sehari-hari.

Namun meskipun demikian perilaku sopan santun juga tidak sepenuhnya berkaitan dengan pola asuh orang tua, terdapat faktor lain yang memiliki peran dalam pembetukan perilaku sopan santun anak, seperti teman sebaya, lingkungan, maupun orang yang dianggap sebagai model bagi anak.

\section{Saran}

1. Bagi madrasah, hasil penelitian ini diharapkan dapat digunakan sebagai bahan pertimbangan bagi madrasah dalam mengambil kebijakan baik itu sikap-sikap maupun tindakan untuk menanamkan perilaku sopan santun yang baik.

2. Bagi orang tua dan guru, hasil penelitian ini diharapkan dapat digunakan sebagai bahan referensi orang tua maupun guru dalam membimbing dan mengarahkan anak memilih pola asuh yang sesuai dengan karakter anak serta sebaiknya orang tua dan guru lebih memperhatikan anak mereka.

3. Bagi peneliti yang akan datang, hasil penelitian ini diharapkan menjadi bahan rujukan dalam melakukan penelitian yang berkaitan dengan pola asuh orang tua dan perilaku sopan santun anak, karena selain pola asuh orang tua masih banyak faktorfaktor yang mempengaruhi perilaku sopan santun.

\section{Daftar Pustaka}

Anisah, Ani Siti. "POLA ASUH ORANG TUA DAN IMPLIKASINYA TERHADAP PEMBENTUKAN KARAKTER ANAK." Jurnal Pendidikan UNIGA 5, no. 1 (February 20, 2017): 70-84. http://journal.uniga.ac.id/index.php /JP/article/view/43.

Fathurrohman, Pupuh. Pengembangan Pendidikan Karakter. Bandung: Refika Aditama, 2013.

Mansur. Pendidikan Anak Usia Dini Dalam Islam. Jakarta: Pustaka Pelajar, 2005.

Maulida, Awalina. "Hubungan Pengunaan Bahasa Jawa Krama Dengan Perilaku Siswa MIN Kecandran Salatiga Tahun 2012." STAIN Salatiga, 2012.

Mu'niah. Materi Pendidikan Agama Islam Untuk Perguruan Tinggi. Yogyakarta: Ar-Ruzz Media, 2011.

Muslich, Mansur. Pendidikan Karakter Menjawab Tantangan Krisis Multidimensional,. Jakarta: Bumi Aksara, 2013.

Noor, Rohiniah M. Orang Tua Bijaksana Anak Bahagia. Yogyakarta: Ar-Ruzz Media, 2009.

Purwanto, Nanang. Pengantar Pendidikan. Yogyakarta: Graha Ilmu, 2015.

Risthantri, Putri, and Ajat Sudrajat. "HUBUNGAN ANTARA POLA ASUH ORANG TUA DAN KETAATAN BERIBADAH DENGAN PERILAKU SOPAN SANTUN PESERTA DIDIK." Harmoni Sosial: Jurnal Pendidikan IPS 2, no. 2 (September 30, 2015): 191202.

https://doi.org/10.21831/hsjpi.v2i2. 7670.

Shochib, Moh. Pola Asuh Orang Tua. 
Jakarta: Rineka Cipta, 2000.

Siregar, Syofian. Statistik Parametrik

Untuk Penelitian Kuantitatif. Jakarta:

Bumi Aksara, 2014.

Sugiyono. Metode Penelitian Pendidikan

(Pendekatan Kuantitatif, Kualitatif,

Dan R\&D). Bandung: Alfabeta, 2013.

Suharti. "Pendidikan Sopan Santun Dan

Kaitannya Dengan Prilaku Berbahasa Jawa Mahasiswa." Diksi 1, no. 1 (2004).

Wahyudi, Didik, and I Made Arsana.

"PERAN KELUARGA DALAM

MEMBINA SOPAN SANTUN ANAK DI

DESA GALIS KECAMATAN GALIS

KABUPATEN PAMEKASAN." Kajian

Moral Dan Kewarganegaraan 1, no. 2 (2014): 290-304.

https://jurnalmahasiswa.unesa.ac.id /index.php/jurnal-pendidikan-

kewarganegaraa/article/view/6706.

Wulansari, Andhita Dessy. Penelitian

Pendidikan: Suatu Pendekatan

Praktik Dengan Menggunakan SPSS.

Ponorogo: STAIN Ponorogo Press,

2012. 